\title{
Regulation of Serotonin-Stimulated Phosphoinositide Hydrolysis: Relation to the Serotonin 5-HT-2 Binding Site
}

\author{
P. Jeffrey Conn' and Elaine Sanders-Bush \\ Departments of Pharmacology and Psychiatry, Vanderbilt University School of Medicine, Nashville, Tennessee \\ 37232
}

The hypothesis that serotonin (5-HT)-stimulated phosphoinositide hydrolysis is mediated by the 5-HT-2 binding site in cerebral cortex was tested by comparing antagonist $K_{d}$ values determined by Schild analyses with $K_{\mathrm{i}}$ values at the 5-HT-2 binding site. A significant correlation was found between $K_{d}$ values and $K_{\mathrm{i}}$ values at competing for ${ }^{3} \mathrm{H}$-ketanserin binding $(R=0.98)$, suggesting that the phosphoinositide-linked receptor and the 5-HT-2 site are identical. The 5-HT-2-mediated phosphoinositide response was then used as a measure of 5-HT-2 receptor sensitivity after in vivo treatments that alter the availability of 5-HT. Chronic treatment with the 5-HT-2 antagonist mianserin resulted in a significant decrease $(52 \%)$ in the density of 5-HT2 binding sites and a significant decrease (49\%) in the maximal phosphoinositide hydrolysis response to 5-HT. Depletion of 5-HT levels with para-chlorophenylalanine or chemical denervation of serotonergic neurons with 5,7-dihydroxytryptamine had no significant effect upon 5-HT-2 receptor density or upon the phosphoinositide response to 5-HT. These data suggest that changes or lack of changes in 5-IIT-2 receptor density following in vivo manipulations reflect the functional state of the receptor.

Central serotonin (5-HT) receptors are divided into 2 broad subclasses based upon radioligand binding data (Leysen et al., 1982; Peroutka and Snyder, 1979). The 5-HT-1 sitc is labeled with ${ }^{3} \mathrm{H}-5-\mathrm{HT}$, whereas the $5-\mathrm{HT}-2$ site is labeled with the $5-\mathrm{HT}$ antagonists, ${ }^{3} \mathrm{H}$-spiroperidol and ${ }^{3} \mathrm{H}$-ketanserin. Recent evidence suggests that the 5-HT-1 site can be further divided into at least 3 subtypes (Pazos et al., 1984; Pedigo et al., 1981; Yagaloff and Hartig, 1985). For the most part, the 5-HT-1 site responds predictably to in vivo manipulations that alter 5-HT availability. Chemical denervation induces an increase in the density of ${ }^{3} \mathrm{H}-5-\mathrm{HT}$ binding sites in the hippocampus (Nelson et al., 1978; Seeman et al., 1980), and inhibition of 5-HT inactivation with monoamine oxidase inhibitors (Savage et al., $1980 \mathrm{~b}$ ), or by chronic reuptake blockade (Dumbrille-Ross and Tang, 1983; Wong and Bymaster, 1981), reduces the number of 5-HT-1 binding sites. Furthermore, chronic treatment with 5-HT receptor agonists, or antagonists, decreases, or increases,

\footnotetext{
Received Mar. 10, 1986; revised May 14, 1986; accepted June 4, 1986

The expert technical assistance of Ms. Deborah Mays and Ms. Marsha Breeding is gratefully acknowledged. Also we appreciate the following companies for generously donating the samples of drugs used in this study: Abbott Laboratories, Janssen Pharmaceutica, Mead Johnson and Co., Merrell Dow Research Institute, Wyeth Laboratories, Sandoz Pharmaceuticals, and E. R. Squibb and Sons. This work was supported by Alcohol, Drug Abuse and Mental Health Administration Research Grants MH 34007 and MH 26463 from the National Institute of Mental Health; the Tennessee Department of Mental Health and Mental Retardation; and a graduate fellowship from Lilly Research Laboratories (P.J.C.).

Correspondence should be addressed to Dr. Elaine Sanders-Bush, Department of Pharmacology, Vanderbilt University School of Medicine, Nashville, TN 37232.

Present address: Department of Pharmacology, Yale University School of Medicine, New Haven, CT 06510
}

Copyright (C) 1986 Society for Neuroscience 0270-6474/86/123669-07\$02.00/0 the density of 5-HT-1 binding sites, respectively (Samanin et al., 1980; Savage et al., 1980a). The 5-HT-2 site, on the other hand, does not respond predictably to in vivo manipulations. It does not develop increased densily after denervation (Blackshear et al., 1981; Quik and Azmita, 1983; Seeman et al., 1980) and is not down-regulated after chronic 5-HT reuptake blockade (Dumbrille-Ross and Tang, 1983; Peroutka and Snyder, 1980). Paradoxically, chronic treatment with putative 5-HT antagonists results in a down-regulation of the 5-HT-2 binding site (Blackshear and Sanders-Bush, 1982; Blackshear et al., 1983).

It is possible that 5-HT-2 receptor sensitivity does respond predictably to in vivo manipulations and that the observed changes (or lack of changes) in 5-HT-2 receptor density are not accompanied by parallel changes in the responsiveness to 5-IIT. Studies of behavioral models of 5-HT-2 activation, although not entirely consistent, lend support to this hypothesis. For instance, chemical denervation of 5-HT neurons has no effect on $5-\mathrm{HT}-2$ receptor density, but it does induce supersensitivity in the head twitch model of 5-HT-2 receptor activation (Nakamura and Fukushima, 1978; Yamamoto and Ueki, 1981). Futhermore, there are reports that chronic administration of putative 5-HT-2 antagonists induces supersensitivity in behavioral models of 5-HT-2 activation (Friedman et al., 1983; Mogilnicka and Klimck, 1979; Stoltz ct al., 1983). Other groups have failed to confirm this; instead, they found subsensitivity after chronic antagonists (Blackshear and Sanders-Bush, 1982; Lucki et al., 1985). Although such behavioral responses are clearly mediated by the 5-HT-2 binding site, nonserotonergic neuronal systems undoubtedly come into play, making interpretation of the behavioral results complicated. For instance, behavioral supersensitivity to a 5-HT-2 agonist could represent the loss of inhibitory input from another system rather than 5-HT-2 receptor supersensitivity. Furthermore, it is conceivable that changes in the density of the 5-HT-2 site, which are usually measured in frontal cortex, do not occur on cells involved in mediating the behavioral responses. For these reasons, it would be advantageous to study a $5-\mathrm{HT}-2$-mediated response that is closely linked to the receptor. This would allow a direct measurement of the relationship between 5-HT-2 receptor density and 5-HT-2 receptor sensitivity.

One response that could serve this purpose is 5-HT-stimulated phosphoinositide hydrolysis. Phosphoinositide hydrolysis is a multifunctional transmembrane transducing mechanism that results in release of at least 2 second messengers (inositol-1,4,5trisphosphate and diacylglycerol). These second messengers elicit a number of cellular responses, including neurotransmitter release, lysosomal enzyme release, glycogenolysis, DNA synthesis, photoreception, platelet aggregation, and heterologous receptor desensitization (Berridge, 1984). Recently, it has been suggested that 5-HT-stimulated phosphoinositide hydrolysis in human platelets (de Chaffoy de Courcelles et al., 1985), rat aorta (Roth et al., 1984, 1985), and rat cerebral cortex (Conn and 
Sanders-Bush, 1984,1985$)$ is mediated by the 5 -HT- 2 binding site. In cerebral cortex, however, a poor correlation between antagonist potencies at blocking 5-HT-stimulated phosphoinusitide hydrolysis and competing for 5-HT-2 binding prevented an unequivocal conclusion.

In the present study, we further test the hypothesis that 5-HTstimulated phosphoinositide turnover in cerebral cortex is mediated by the $5-\mathrm{HT}-2$ binding site by using Schild analyses to estimate absolute potencies ( $K_{\mathrm{d}}$ values) of 5-IIT-2 antagonists for the phosphoinositide-linked receptor. Comparison of these values with affinities at the $5-\mathrm{HT}-2$ binding site gave a significant correlation, supporting this hypothesis. The 5-HT-2-mediated phosphoinositide response was then used to measure 5-HT-2 responsiveness after chronic administration of the 5-HT antagonist, mianserin, or after 5-HT depletion or destruction of serotonergic neurons with para-chlorophenylalanine (PCPA) or 5,7dihydroxytryptamine (5,7-DHT), respectively

\section{Materials and Methods}

\section{Drugs}

PCPA methyl ester $\mathrm{HCl}, 5-\mathrm{HT}$ creatinine sulfate, 5,7-DHT creatinine sulfate, phosphatidylinositol phosphate (PIP) and phosphatidylinositol bisphosphate (PIP2) were purchased from Sigma Chemical Co. (St. Louis, MO); phosphatidylinositol (PI) and Lyso PI from Avanti Polar Lipids Inc. (Birmingham, AL); pentobarbital sodium from Abbott Laboratories (North Chicago, IL); and mianserin $\mathrm{HCl}$ from Research Biochemicals Inc. (Wayland, MA). The following drugs were kindly donated by the indicated manufacturers: ketanserin tartrate, spiperone, and pipamperone $\mathrm{HCl}$ from Janssen Pharmaceutica (Beerse, Belgium); promethazine $\mathrm{HCl}$ from Wyeth Laboratories (Philadelphia, PA); desipramine $\mathrm{HCl}$ from Merrell Dow Research Institute (Cincinnati, $\mathrm{OH}$ ); clozapine and pizotifen from Sandoz, Inc. (East Hanover, NJ); cinanserin $\mathrm{HCl}$ from E. R. Squibb and Sons (Princeton, NJ); pargyline $\mathrm{HCl}$ from Abbott Laboratories (North Chicago, IL); trazadone $\mathrm{HCl}$ from Mead Johnson and Co. (Evansville, IN). ${ }^{3} \mathrm{H}$-ketanserin $\mathrm{HCl}(78.6 \mathrm{Ci} /$ mmol) was purchased from New England Nuclear (Boston, MA) and ${ }^{3} \mathrm{H}$-myo-inositol ( $14 \mathrm{Ci} / \mathrm{mmol}$ ) from American Radiolabeled Chemicals (St. Louis, MO).

\section{Levels of phosphoinositides}

The levels of radioactivity in PIP and PIP2 and the specific radioactivity of PI were determined by established methodologies. Cerebral cortices from male Sprague-Dawley rats were dissected and sliced as described previously (Conn and Sanders-Bush, 1985). Slices were incubated for $30 \mathrm{~min}\left(37^{\circ} \mathrm{C}\right)$ in a gently shaking bath in Krebs bicarbonate buffer containing $10 \mathrm{~mm}$ glucose (KRBG). Slices were then washed with warm $\mathrm{KRBG}$ and $300 \mu \mathrm{l}$ aliquots of gravity-packed slices were added to vials containing $12 \mu \mathrm{Ci}{ }^{3} \mathrm{H}$-inositol in $3.3 \mathrm{ml} \mathrm{KRBG}$ and incubated for an additional $3 \mathrm{hr}\left(37^{\circ} \mathrm{C}\right)$. Free ${ }^{3} \mathrm{H}$-inositol was washed away with warm KRBG containing $10 \mathrm{~mm}$ myo-inositol and $200 \mu \mathrm{l}$ aliquots of gravitypacked slices were transferred to conical centrifuge tubes and rapidly homogenized using a Brinkman polytron. The lipids were immediately extracted as described by Schacht (1981). The lipid extract was divided into 4 fractions and evaporated under a stream of nitrogen while kept on ice.

The method of Yavin and Zutra (1977) was used to separate PI from other phospholipids. This method employs 2-dimensional thin-layer chromatography (ILC) and gives excellent separation of PI from phosphatidylserine compared with other TLC methods. Briefly, fractions were spotted on Brinkman silica gel $G$ plates and developed in the first dimension using chloroform $/$ methanol $/ 40 \%$ methylamine $(13: 6: 1.5)$. The plates were dried under warm air and exposed to fumes of $\mathrm{HCl}$ to neutralize the methylamine. The plates were then developed in a solvent system consisting of chloroform/acetone/methanol/acetic acid/water (10: $4: 2: 3: 1$ ). The dried plates were sprayed with Enhance (New England Nuclear) and exposed to X-ray film for 2-3 d. Only 1 radioactive spot was visible. This corresponds to PI as determined by TLC of standards run simultaneously. The spot corresponding to PI was scraped into acidwashed test tubes for the determination of phosphate. Phosphate content was determined by the method of Van Dongen et al. (1985), using
$\mathrm{KH}_{2} \mathrm{PO}_{4}$ as a standard. Two of the 4 fractions were analyzed in this manner and the values were averaged.

Radioactivity in all 3 phosphoinositides was determined in the second pair of fractions. Samples were spotted on silica gel 60 plates (American Scientific) and run in 1-dimension using chloroform $/$ methanol $/ 4 \mathrm{~N}$ $\mathrm{NH}_{4} \mathrm{OH}$ as the solvent system (Gonzalez-Sastre and Folch-Pi, 1968). Standard nonlabeled phosphoinositides were run simultaneously, and the spots were visualized with iodine vapor. The $R_{\mathrm{f}}$ values of PI, PIP, and PIP2 were $0.59,0.34$, and 0.12 , respectively. Sections, $1 \mathrm{~cm}$, were scraped into counting vials and the radioactivity quantitated by liquid scintillation counting. Only 4 radioactive peaks were found, 3 of which agree with the 3 phosphoinositide standards. The fourth radioactive peak (which represented less than $10 \%$ of the radioactivity spotted) had an $R_{\mathrm{f}}$ value (0.47), which corresponded with a lyso PI standard.

\section{Radioligand binding}

For competition binding studies, the binding of ${ }^{3} \mathrm{H}$-ketanserin was measured in buffer containing physiological salts as described previously (Conn and Sanders-Bush, 1985). $\mathrm{IC}_{50}$ values were determined from Hill plots of competition binding data. $K_{\mathrm{i}}$ values were calculated by the method of Cheng and Prusoff (1973). Scatchard analyses of ${ }^{3} \mathrm{H}-\mathrm{ketan}-$ serin binding were performed as previously described (Conn and Sanders-Bush, 1985), except that physiological salts were omitted.

\section{Phosphoinositide hydrolysis}

Measurement of agonist-induced phosphoinositide hydrolysis was as described previously (Conn and Sanders-Bush, 1985) except that $25 \mu \mathrm{l}$ aliquots of gravity-packed slices were labeled for various times in tubes containing $1-2 \mu \mathrm{Ci}{ }^{3} \mathrm{H}$-inositol and $200 \mu \mathrm{l} \mathrm{KRBG}$. Drugs were added directly to these tubes, and subsequent incubations were in the continuous presence of ${ }^{3} \mathrm{H}$-inositol. Pargyline $(10 \mu \mathrm{M})$ and $\mathrm{LiCl}(10 \mathrm{~mm})$ were routinely added to the incubation medium. Pargyline shifts the 5-HT concentration response curve leftward and eliminates the nonspecific effects of high concentrations of 5-HT (Conn and Sanders-Bush, 1985). Lithium inhibits the metabolism of inositol phosphate (IP) and allows the direct measurement of ${ }^{3} \mathrm{H}$-IP released from labeled phosphoinositides (Berridge et al., 1982). ${ }^{3} \mathrm{H}$-inositol was stored with a small amount of Dowex-1 anion-exchange resin in the formate form in order to maintain purity.

The specific radioactivity of PI increases linearly with increasing labeling incubation time, and the ratio of radioactivity in PIP and in PIP2 relative to PI remains constant (data not shown). Furthermore, the radioactivity present in ${ }^{3} \mathrm{H}$-IP increases linearly with increasing labeling time, but the percentage-response to 5-HT is independent of labeling time (data not shown). Thus, different labeling times $(1-3 \mathrm{hr})$ were used depending on the particular needs of the experiments. For Schild analyses, it was important to have maximum labeling of IP in order to increase the accuracy of $\mathrm{EC}_{50}$ estimates. For this reason, slices were labeled for $3 \mathrm{hr}$. After lesioning with 5,7-DHT, it was necessary to reduce incubation time to $1 \mathrm{hr}$ in order to preserve the integrity of the tissue. In these samples, $2 \mu \mathrm{Ci}$ of ${ }^{3} \mathrm{H}$-inositol was added rather than the usual $1 \mu \mathrm{Ci}$. For all other experiments, labeling was for $2 \mathrm{hr}$.

\section{Schild analyses}

Antagonist $K_{\mathrm{d}}$ values at the phosphoinositide-linked receptor were estimated using the method of Arunlakshana and Schild (1959). Briefly, the concentration response curve of 5-HT was determined in the presence of various concentrations of antagonists. The 5-HT concentrationresponse curves were progressively shifted to the right with increasing concentrations of antagonists. $\mathrm{EC}_{50}$ values of 5-HT were determined at each antagonist concentration, and dose ratio (DR) values were calculated by dividing the $\mathrm{EC}_{50}$ of $5-\mathrm{HT}$ in the absence of antagonist by the $\mathrm{EC}_{50}$ of 5-HT in the presence of antagonist. If the regression analysis of $\log (\mathrm{DR}-1)$ versus $-\log$ antagonist concentration was consistent with a straight line with a slope of unity, this was interpreted as indicative of competitive antagonism (Arunlakshana and Schild, 1959). In cases where competitive antagonism was found, extrapolation of the regression line to the $X$-axis gave a value theoretically equal to the negative $\log$ of the $K_{\mathrm{d}}$ value of that antagonist for the phosphoinositide-linked receptor (pA2).

\section{Monoamine levels}

Monoamine levels in hippocampus were determined by high-pressure liquid chromatography with electrochemical detection (HPLC-EC). The 


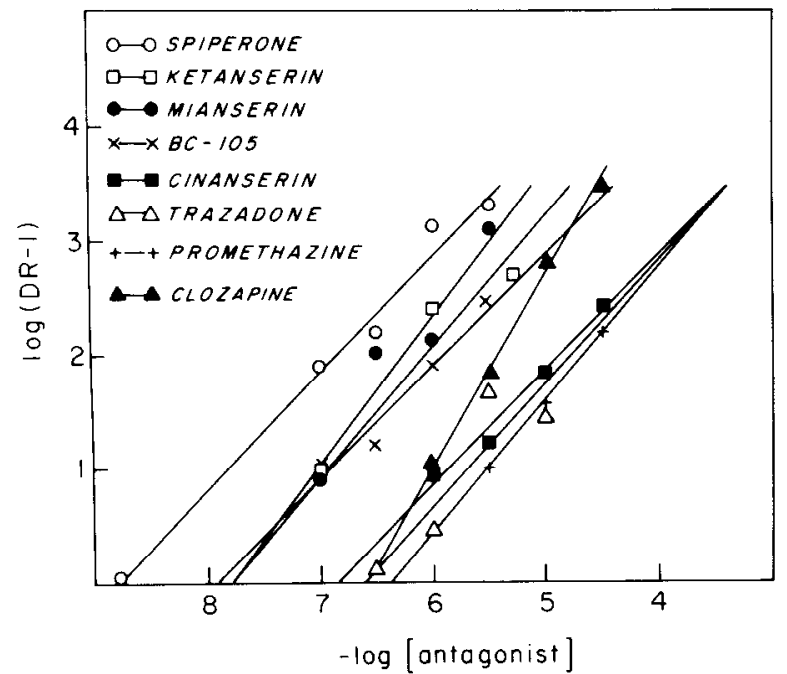

Figure 1. Schild regressions of the effects of antagonists at the phosphoinositide-linked 5-HT receptor. $\mathrm{EC}_{50}$ values for $5-\mathrm{HT}$ at stimulating phosphoinositide hydrolysis were determined in the presence or absence of various concentrations of antagonists. The dose ratio $(D R)$ was determined by dividing 5-HT's $\mathrm{EC}_{50}$ value in the presence of antagonist by the $\mathrm{EC}_{50}$ value in the absence of antagonist. $\log (\mathrm{DR}-1)$ is plotted as a function of $-\mathrm{log}$ antagonist concentration. Each regression represents values determined from 4-8 5-HT concentration-response curves.

HPLC apparatus consisted of a Bioanalytical Systems (West Lafayette, IN) model LC-304 liquid chromatograph equipped with an electrochemical detector and a glassy carbon electrode set at $+0.75 \mathrm{~V}$. A modification of the method of Mayer and Shoup (1983) was employed using a mobile phase of $6 \%$ acetonitrile in buffer, a column temperature of $25^{\circ} \mathrm{C}$, and a single electrode. $N$-Methylserotonin was routinely added as an internal standard.

\section{In vivo drug treatments}

Male Sprague-Dawley rats were obtained from Harlan Sprague Dawley, Inc. (Indianapolis, IN). Three different in vivo manipulations were used to alter 5-HT availability. For each of these treatments, a control group of animals was injected with vehicle only.

Mianserin-treated rats were injected subcutaneously with mianserin $(5 \mathrm{mg} / \mathrm{kg}$ ) daily for 10 consecutive days. Animals were sacrificed $48 \mathrm{hr}$ after the last injection, and cerebral cortices were dissected and used for

\section{Table 1. Relationship between potencies at phosphoinositide-linked} receptor and 5-HT-2 binding site

\begin{tabular}{|c|c|c|c|c|c|}
\hline \multirow[b]{2}{*}{ Antagonist } & \multicolumn{4}{|c|}{ Schild plot } & \multirow{2}{*}{$\begin{array}{l}5 \text {-HT-2 } \\
\text { binding, } \\
K_{\mathrm{d}}(\mathrm{nM})\end{array}$} \\
\hline & Slope & $r$ & $\mathrm{pA}_{2}$ & $K_{\mathrm{d}}(\mathrm{nM})$ & \\
\hline Spiperone & 1.0 & 0.97 & 8.80 & 2 & $2.0 \pm 0.6$ \\
\hline Ketanserin & 1.1 & 0.96 & 7.93 & 12 & $3.1 \pm 0.8$ \\
\hline Pizotifen & 1.0 & 0.97 & 7.92 & 12 & $4.4 \pm 1.5$ \\
\hline Mianserin & 1.2 & 0.98 & 7.86 & 14 & $5.0 \pm 0.4$ \\
\hline Cinanserin & 1.0 & 0.99 & 6.83 & 148 & $21 \pm 6.2$ \\
\hline Trazadone & 1.0 & 0.91 & 6.60 & 240 & $24 \pm 5.0$ \\
\hline Clozapine & 1.5 & 1.0 & & & $34 \pm 6.4$ \\
\hline Promethazine & 1.2 & 1.0 & 6.30 & 500 & $52 \pm 5.8$ \\
\hline
\end{tabular}

Binding of 0.6 nм ${ }^{3} \mathrm{H}$-ketanserin to broken membranes was measured in buffer identical to that used in the phosphoinositide hydrolysis assays except that $25 \mathrm{~mm}$ sodium bicarbonate was replaced with $25 \mathrm{~mm}$ Tris. The $K_{d}$ values at the phosphoinositide-linked receptor were determined by taking the antilog of the $X$ intercept of the Schild regressions shown in Figure 1. The binding values represent the means \pm SEM of 4-9 separate experiments each done in duplicate or triplicate.

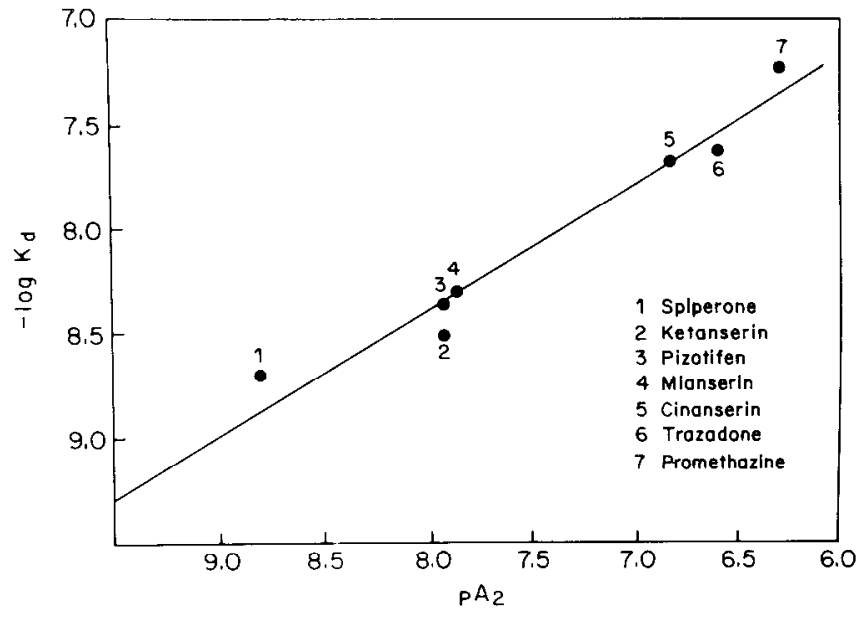

Figure 2. Comparison of Schild-determined $K_{\mathrm{d}}$ values versus $K_{\mathrm{i}}$ values determined from radioligand competition binding. Data are taken from Table 1. The correlation coefficient obtained from linear-regression analysis was $0.98(p<0.001)$.

measurement of phosphoinositide hydrolysis, ${ }^{3} \mathrm{H}$-ketanserin binding, or phospholipid levels.

PCPA-treated animals were injected intraperitoneally with $200 \mathrm{mg} /$ $\mathrm{kg}$ daily for 4 consecutive days. Rats were sacrificed $48 \mathrm{hr}$ after the last injection, and cerebral cortices were dissected and used for measurement of ${ }^{3} \mathrm{H}$-ketanserin binding, phosphoinositide hydrolysis, or phospholipid levels. Hippocampi were dissected as described by Glowinski and Iversen (1966) for the determination of monoamine levels.

The neurotoxin 5,7-DHT was injected intraventricularly according to the method of Janowsky et al. (1982). Sixty minutes before injection of the neurotoxin, desipramine $(25 \mathrm{mg} / \mathrm{kg}$, i.p.) was administered to protect noradrenergic neurons (Björklund et al., 1975). 5,7-DHT, 150 $\mu \mathrm{g}$ dissolved in $20 \mu \mathrm{l}$ of $0.9 \%$ saline containing $0.1 \%$ ascorbic acid, was injected into the lateral ventricle over a period of $5 \mathrm{~min}$. Control rats received desipramine and an intraventricular injection of vehicle. Nine to $12 \mathrm{~d}$ after surgery, animals were sacrificed, and cerebral cortices were dissected and used for ${ }^{3} \mathrm{H}$-ketanserin binding or for the measurement of phosphoinositide hydrolysis. The levels of monoamines in hippocampi were determined as an index of the effect of the lesion.

\section{Results}

\section{Schild analyses}

The 5-HT antagonists - spiperone, ketanserin, pizotifen, mianserin, cinanserin, trazadone, clozapine, and promethazinecaused concentration-dependent rightward shifts of the 5-HT concentration response curves. The Schild regression lines of these data gave slopes close to unity for all antagonists except clozapine (Fig. 1, Table 1). The Schild slope of clozapine was 1.5 , indicating that this drug may not interact with the phosphoinositide-linked receptor in a simple competitive manner. Thus, a $K_{\mathrm{d}}$ value of clozapine at the phosphoinositide-linked receptor could not be determined.

$K_{\mathrm{i}}$ values at the ${ }^{3} \mathrm{H}$-ketanserin labeled $5-\mathrm{HT}-2$ binding site were estimated from competition binding data (Table 1). The rank order of the antagonists' potencies at the phosphoinositidelinked receptor was identical to the rank order for inhibition of binding to the 5-HT-2 site. Furthermore, regression analysis of the $K_{\mathrm{d}}$ values at the phosphoinusitide-linked receptor versus $K_{\mathrm{i}}$ values at the 5-HT-2 site (Fig. 2) gave a correlation coefficient of $0.98(p<0.001) . K_{d}$ values estimated by Schild analyses were generally higher than those determined in radioligand binding assays. Different tissue preparations (slices versus homogenates) were used for the two assays, which may explain the observed differences in potencies. 


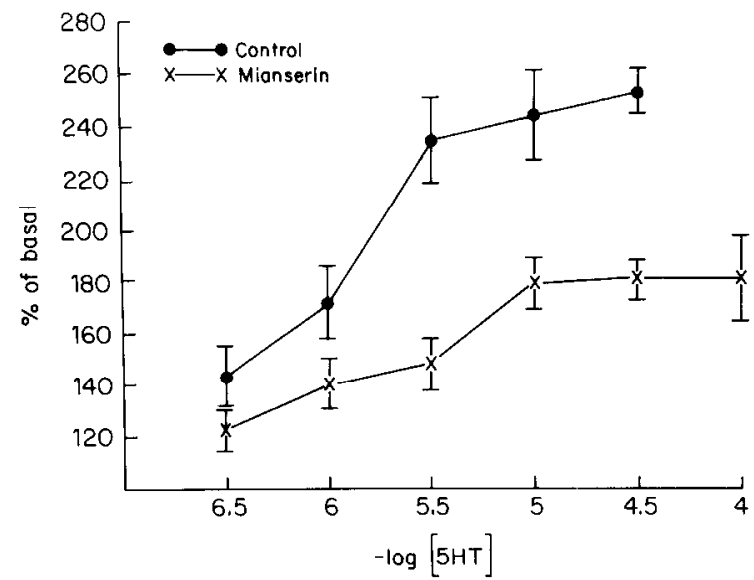

Figure 3. Effect of chronic mianserin treatment on 5-HT-stimulated phosphoinositide hydrolysis. Labeled cerebral cortical slices were incubated with increasing concentrations of 5-HT and the amount of radioactivity present in ${ }^{3} \mathrm{H}$-IP was measured as described in Materials and Methods. Data are presented as the percentage of basal radioactivity $(427 \pm 42 \mathrm{cpm}$ for control; $269 \pm 45 \mathrm{cpm}$ for treated). The values are the means of 4 separate experiments, each done in triplicate. Each experiment included a dose-response for 1 control and 1 treated animal. Vertical bars, SEM.

\section{Chronic treatments}

Scatchard analyses of ${ }^{3} \mathrm{H}$-ketanserin binding in cerebral cortices of rats treated chronically with mianserin showed a significant reduction ( $48 \%$ of control) in the density of 5-HT-2 binding sites with no effect upon the $K_{\mathrm{d}}$ value (Table 2). Two-way analysis of variance (ANOVA) revealed a significant main effect of mianserin treatment $(p<0.001)$ upon 5-HT-stimulated phosphoinositide hydrolysis in cerebral cortical slices (Fig. 3). Mianserin treatment caused a significant reduction ( $51 \%$ of control) in the maximal phosphoinositide response elicited by 5-HT, with no change in the $\mathrm{EC}_{50}$ value. The $\mathrm{EC}_{50}$ values of $5-\mathrm{HT}$ in control and treated rats were $1.3 \pm 0.4$ and $2.4 \pm 1.0 \mu \mathrm{M}$, respectively. The specific radioactivity of PI and the relative radioactivity in the polyphosphoinositides were not altered by the treatment (Table 2).

Chronic administration of PCPA had no significant effect upon the density of 5-HT-2 binding sites or upon the affinity of ${ }^{3} \mathrm{H}-$ ketanserin at the 5-HT-2 binding site (Table 2). Furthermore,

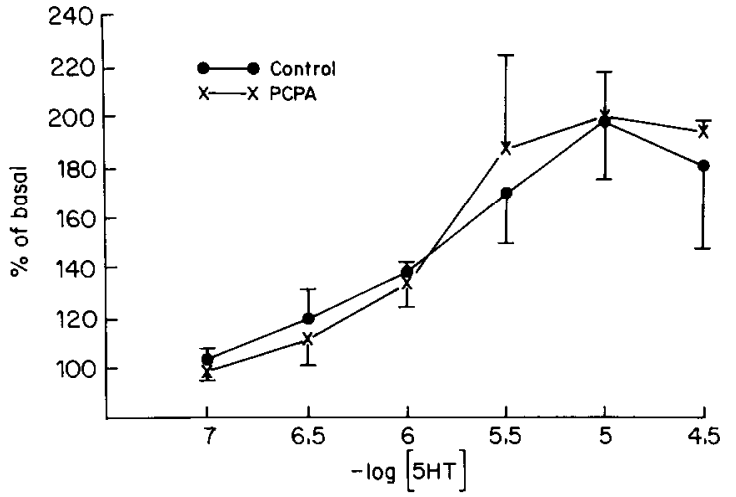

Figure 4. Effect of chronic PCPA on 5-HT-stimulated phosphoinositide hydrolysis. Phosphoinositide hydrolysis was measured as described in Figure 3 in cerebral cortical slices from rats that had received chronic administration of either PCPA or water. Data are presented as the percentage of basal radioactivity $(303 \pm 51 \mathrm{cpm}$ for control; $460 \pm$ $67 \mathrm{cpm}$ for treated). The values are the means of 3 separate experiments each done in triplicate. Each experiment included a dose-response for 1 control and 1 treated animal. Vertical bars, SEM.

this treatment did not change the cerebral cortical phosphoinositide response to 5-HT (Fig. 4) or the radioactivity present in the phosphoinositides (Table 2). PCPA caused a greater than $97 \%$ reduction in the levels of 5-HT and 5-hydroxyindoleacetic acid (5-HIAA) with no statistically significant effect upon levels of norepinephrine (data not shown).

Chemical denervation with 5,7-DHT resulted in a $90 \%$ depletion of 5-HT and 5-HIAA with no significant effect upon NE levels (data not shown). Treatment with 5,7-DHT did not change the density of 5-HT-2 hinding sites or the $K_{\mathrm{d}}$ value of ${ }^{3} \mathrm{H}-\mathrm{ke}-$ tanserin (Table 2). Furthermore, this treatment had no significant effect upon the maximum phosphoinositide response to 5-HT (Fig. 5). The 5-HT concentration response curve was slightly shifted to the left in lesioned animals but 2-way ANOVA revealed that the main effect of lesions was not statistically significant $(p=0.09)$. The $\mathrm{EC}_{50}$ value of 5-HT was less in 6 of the 7 lesioned rats compared with controls analyzed simultaneously: mean $\mathrm{EC}_{50}$ values in control and lesioned rats of $0.61 \pm$ 0.1 and $0.38 \pm 0.1$, respectively. However, the difference in $\mathrm{EC}_{50}$ values did not reach statistical significance $(p=0.1) .5,7$ DHT treatment had no effect upon the incorporation of ${ }^{3} \mathrm{H}-$ inositol into any of the phosphoinositides (Table 2).

\section{Table 2. Effect of chronic treatments on ${ }^{3} \mathrm{H}$-ketanserin binding and ${ }^{3} \mathrm{H}$-phosphoinositides}

\begin{tabular}{|c|c|c|c|c|c|c|c|c|}
\hline \multirow[b]{3}{*}{ Group } & \multicolumn{2}{|c|}{${ }^{3} \mathrm{H}$-ketanserin binding } & \multicolumn{6}{|c|}{${ }^{3} I I$-phosphoinositides } \\
\hline & \multirow{2}{*}{$\begin{array}{l}K_{\mathrm{d}} \\
\text { (nM) }\end{array}$} & \multirow{2}{*}{$\begin{array}{l}B_{\max } \\
\text { (fmol/mg } \\
\text { protein) }\end{array}$} & \multicolumn{2}{|l|}{ PI } & \multicolumn{2}{|l|}{ PIP } & \multicolumn{2}{|l|}{ PIP2 } \\
\hline & & & $\overline{\mathrm{nCi}}$ & $\mathrm{nCi} / \mathrm{nmol}$ & $\overline{\mathrm{nCi}}$ & PI/PIP & $\mathrm{nCi}$ & PI/PIP2 \\
\hline Mianserin & $2.2 \pm 0.40$ & $100 \pm 1^{a}$ & $56 \pm 1.8$ & $1.9 \pm 0.13$ & $5.4 \pm 0.7$ & 4.8 & $4.0 \pm 0.68$ & 6.5 \\
\hline Vehicle & $0.93 \pm 0.07$ & $172 \pm 17$ & $7.5 \pm 0.96$ & $0.38 \pm 0.05$ & $4.0 \pm 0.4$ & 1.9 & $2.5 \pm 0.48$ & 3.0 \\
\hline PCPA & $0.89 \pm 0.07$ & $191 \pm 26$ & $8.9 \pm 0.32$ & $0.45 \pm 0.02$ & $4.4 \pm 1.0$ & 2.0 & $2.6 \pm 1.10$ & 3.4 \\
\hline 5,7-DHT & $0.67 \pm 0.04$ & $256 \pm 18$ & $51 \pm 5.1$ & $1.8 \pm 0.18$ & $10.0 \pm 1.3$ & 5.1 & $8.0 \pm 1.2$ & 6.4 \\
\hline
\end{tabular}

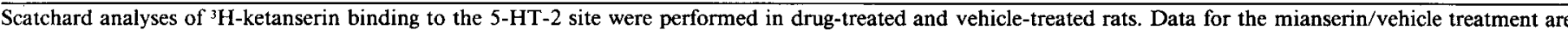

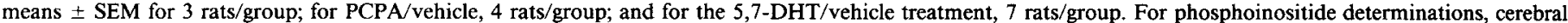

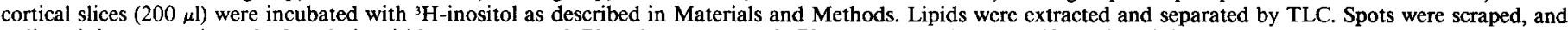

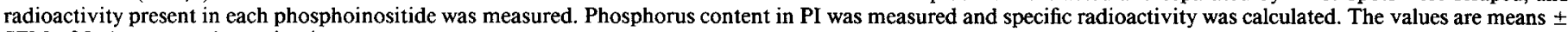
SEM of 3-4 separate determinations.

${ }^{a} p<0.01$. 


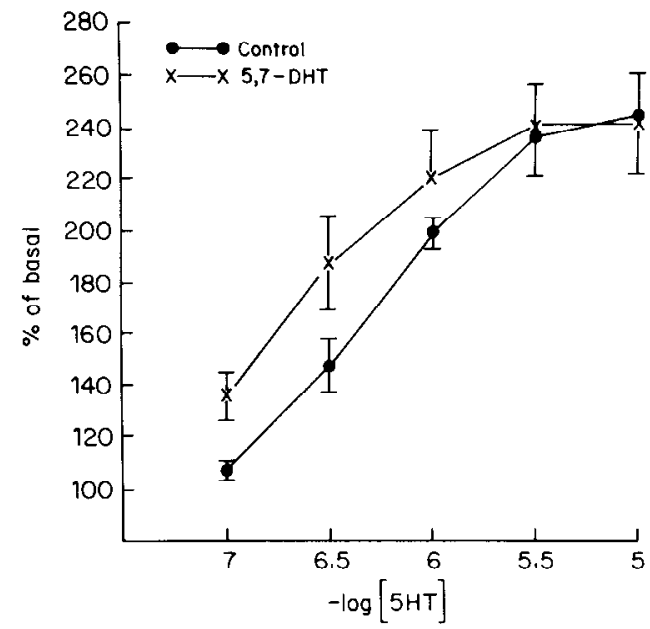

Figure 5. Effect of 5,7-DHT lesions on 5-HT-stimulated phosphoinositide hydrolysis. Phosphoinositide hydrolysis was measured as described in Figure 3 in cerebral cortical slices from rats that had received intraventricular injection of either 5,7-DHT or vehicle. Data are presented as the percentage of basal radioactivity $(657 \pm 62 \mathrm{cpm}$ for control; $628 \pm 97 \mathrm{cpm}$ for treated). The values are the means of 7 separate experiments each done in triplicate. Each experiment included a doseresponse for 1 control and 1 treated animal. Vertical bars, SEM.

\section{Discussion}

The present results confirm previous reports that 5-HT-2 antagonists inhibit 5-HT-stimulated phosphoinositide hydrolysis (Conn and Sanders-Bush, 1984, 1985; de Chaffoy de Courcelles et al., 1985; Kendall and Nahorski, 1985; Roth et al., 1984) and extend those findings by showing that a significant correlation exists between Schild analysis determined $K_{\mathrm{d}}$ values at the cerebral cortical phosphoinositide-linked receptor and $K_{\mathrm{i}}$ values at the 5-HT-2 binding site. The phosphoinositide response to some agonists does not reflect a direct coupling of a receptor to phosphoinositide hydrolysis but is secondary to agonist-induced increases in neurotransmitter release (Bone and Michell, 1985) or arachidonate metabolism (Rittenhouse, 1984; Watson et al., 1985). We have previously shown that 5-HT's eflect on phosphoinositide hydrolysis in cerebral cortical slices apparently is not secondary to either of these indirect mechanisms (Conn and Sanders-Bush, 1986a). Taken together, these data provide strong evidence that phosphoinositide hydrolysis is the transducing mechanism linked to the 5-HT-2 receptor.

5-HT stimulates phosphoinositide hydrolysis in rat choroid plexus with a pharmacology similar to that of the 5-HT-1c binding site (Conn et al., 1986). This recently described binding site is present in high density in the choroid plexus (Pazos et al., 1984; Yagaloff and Hartig, 1985). The 5-HT-1c-mediated phosphoinositide response apparently is not mediated by 5-HTstimulated arachidonate metabolism or neurotransmitter release (Conn and Sanders-Bush, 1986b). Thus, at least 2 5-HT receptor subtypes appear to utilize phosphoinositide hydrolysis for signal transduction. The properties of the phosphoinositide response to activation of these 2 receptors has recently been reviewed (Sanders-Bush and Conn. 1986a, b).

Given the evidence that the 5-HT-2 site is directly coupled to phosphoinositide hydrolysis, we employed this response as a measure of 5-HT-2 receptor activation in order to determine the effect of in vivo manipulations of 5-HT availability upon 5-HT-2 receptor responsiveness. Consistent with previous reports (Blackshear and Sanders-Bush, 1982; Blackshear et al., 1983), chronic administration of the 5-HT-2 antagonist, mianserin, resulted in a marked decrease in the density of 5-HT-2 binding sites ( $48 \%$ of control), with no effect upon the $K_{\mathrm{d}}$ of ${ }^{3} \mathrm{H}$ - ketanserin. This was accompanied by a corresponding decrease in the maximum phosphoinositide response to 5 -HT $(52 \%$ of control), with no effect upon the $\mathrm{EC}_{50}$ value of 5-HT. The excellent agrecment between the percentage decrease in the density of the 5-HT-2 binding site and the maximum phosphoinositide response to 5-HT further supports the hypothesis that the 5-HT-2 site is linked to phosphoinositide hydrolysis. Furthermore, this finding demonstrates that chronic mianserin-induced down-regulation of the 5-HT-2 site is accompanied by $5-\mathrm{HT}-2$ receptor subsensitivity. It is unclear why $5-\mathrm{HT}-2$ antagonists induce this paradoxical desensitization, and it remains a challenge to determine the mechanism by which mianserin and other 5-HT-2 antagonists induce such changes.

Also consistent with previous reports is the finding that chemical lesioning of 5-HT neurons with 5,7-DHT or the administration of PCPA results in profound, selective depletion of 5-HT and its metabolite but has no effect upon the density of the 5-HT-2 binding site (Blackshear et al., 1981; Quik and Azmita, 1983; Seeman et al., 1980). Destruction of noradrenergic neurons has a similar lack of effect upon $\alpha_{1}$-adrenergic receptor density. However, noradrenergic denervation induces a supersensitive $\alpha_{1}$-mediated phosphoinositide response (Akhtar and Abdel-Latif, 1986; Janowsky et al., 1984; Kendall et al., 1985; Zatz, 1985). This suggests that the $\alpha_{1}$-receptor is regulated by alterations in receptor-effector coupling rather than alterations in receptor density. Given the possibility that the 5-HT-2 receptor system is regulated in a similar manner, it was of interest to determine the effect of serotonergic denervation or depletion upon 5-HT-2-mediated phosphoinositide hydrolysis. The current results show that 5-HT-stimulated phosphoinositide hydrolysis was unchanged following these treatments, suggesting that regulation of the 5-HT-2 receptor system is not analogous to regulation of the $\alpha_{1}$-adrenergic receptor.

Lesioning of 5-HT neurons with 5,7-DHT does result in supersensitive 5-HT-2-mediated behavioral responses (Nakamura and Fukushima, 1978; Yamamoto and Ueki, 1981), and some reports indicate that chronic administration of 5-HT-2 antagonists does the same (Friedman et al., 1983; Mogilnicka and Klimek, 1979; Stolz et al., 1982). Evidently, this supersensitivity reflects a change that occurs distal to the receptor/effector complex, since neither the binding nor the transducing mechanism is altered. An example of such regulation exists in $1321 \mathrm{~N} 1$ astrocytoma cells in which sensitivity to muscarinic agonists is regulated by changes in sensitivity of the cell to inositol trisphosphate, a second messenger released upon stimulation of phosphoinositide hydrolysis. This is not accompanied by alterations in muscarinic binding properties or in carbachol-induced phosphoinositide hydrolysis (Masters et al., 1985). Another possible mechanism of regulation, which exists in the CNS, is an alteration of the activity of a neuronal system that is antagonistic to the serotonergic systems involved in these 5-HT-2-mediated behavioral responses. If activity of such a system is decreased following 5-HT denervation, it could result in supersensitive behavioral responses to 5-HT.

Since the assay system used in this study measures the release of radioactivity in IP as an index of phosphoinositide hydrolysis, it is conceivable that in vivo manipulations could alter the specific radioactivity of the phosphoinositide precursors of IP and thus compromise interpretation of the results. However, none of the in vivo drug treatments altered the specific radioactivity of PI or the relative radioactivity in PIP or PIP2. These results suggest that the radioactivity present in IP has the same relation to IP mass in treated and in untreated rats. However, these data do not rule out the possibility that the manipulations specifically alter small phosphoinositide pools that are directly accessible to the $5-\mathrm{HT}-2$ receptor.

In conclusion, the present study provides further evidence that phosphoinositide hydrolysis is the transducing system of 
the 5-HT-2 receptor. Furthermore, this study shows that antagonist-induced 5-HT-2 receptor down-regulation is accompanied by $5-\mathrm{HT}-2$ receptor subsensitivity and that denervation has no effect upon the 5-HT-2 binding site or upon 5-HT-2 receptor sensitivity. Future studies should be aimed at determining the mechanism of development of supersensitivity to 5-HT-2 activation seen in behavioral models of 5-HT-2 activity.

\section{References}

Akhtar, R. A., and A. A. Abdel-Latif (1986) Surgical sympathetic denervation increases alpha-1-mediated accumulation of myo-inositol trisphosphate and muscle contraction in rabbit iris dilator smooth muscle. J. Neurochem. 46: 96-104.

Arunlakshana, O., and H. O. Schild (1959) Some quantitative uses of drug antagonists. Br. J. Pharmacol. 14: 48-58.

Berridge, M. J. (1984) Inositol trisphosphate and diacylglycerol as second messengers. Biochem. J. 220: 345-360.

Berridge, M. J., P. C. Downes, and M. R. Hanley (1982) Lithium amplifies agonist-dependent phosphatidylinositol responses in brain and salivary glands. Biochem. J. 206: 587-595.

Bjorklund, A., O. Lindvall, and A. Nobin (1975) 5,7-Dihydroxytryptamine: Improvement of its selectivity for serotonin neurons in the CNS by pretreatment with desipramine. J. Neurochem. 24: 833-835.

Blackshear, M. A., and E. Sanders-Bush (1982) Serotonin receptor sensitivity after acute and chronic treatment with mianserin. J. Pharmacol. Exp. Ther. 221: 303-308.

Blackshear, M. A., L. R. Steranka, and E. Sanders-Bush (1981) Multiple serotonin receptors: Regional distribution and effect of raphe lesions. Eur. J. Pharmacol. 76: 325-334.

Blackshear, M. A., R. L. Friedman, and E. Sanders-Bush (1983) Acute and chronic effects of serotonin $(5 \mathrm{HT}$ ) antagonists on serotonin binding sites. Naunyn Schmiedebergs Arch. Pharmacol. 324: 125-129.

Bone, E. A., and R. H. Michell (1985) Accumulation of inositol phosphates in sympathetic ganglia: Effects of depolarization and of amine and peptide neurotransmitters. Biochem. J. 227: 263-269.

Cheng, Y., and W. H. Prusoff (1973) Relationship between the inhibition constant $(\mathrm{Ki})$ and the concentration of inhibitor that causes 50 percent inhibition (IC50) of an enzymatic reaction. Biochem. Pharmacol. 22: 3099-3108.

Conn, P. J., and E. Sanders-Bush (1984) Selective 5HT-2 antagonists inhibit serotonin stimulated phosphatidylinositol metabolism in cerebral cortex. Neuropharmacology 8: 993-996.

Conn, P. J., and E. Sanders-Bush (1985) Serotonin stimulated phosphoinositide turnover: Mediation by the $\mathrm{S} 2$ binding site in rat cerebral cortex but not in subcortical regions. J. Pharmacol. Exp. Ther. 234: 195-203.

Conn, P. J., and E. Sanders-Bush (1986a) Biochemical characterization of serotonin stimulated phosphoinositide turnover. Life Sci. 38: 663$669,1986$.

Conn, P. J., and E. Sanders-Bush (1986b) Agonist induced phosphoinositide hydrolysis in rat choroid plexus. J. Neurochem. (in press).

Conn, P. J., E. Sanders-Bush, B. J. Hoffman, and P. R. Hartig (1986) A unique serotonin receptor in choroid plexus is linked to phosphoinositide hydrolysis. Proc. Natl. Acad. Sci. USA 83: 4086-4088.

de Chaffoy de Courcelles, D., J. E. Leysen, F. De Clerk, H. Van Belle, and P. A. J. Janssen (1985) Evidence that phospholipid turnover is the signal transducing system coupled to serotonin-S2 receptor sites. J. Biol. Chem. 260: 7603-7608.

Dumbrille-Ross, A., and S. W. Tang (1983) Noradrenergic and serotonergic input necessary for imipramine-induced changes in beta but not S2 receptor densities. Psychiatr. Res. 9: 207-215.

Friedman, E., T. B. Cooper, and A. Dallob (1983) Effects of chronic antidepressant treatment on serotonin receptor activity in mice. Eur. J. Pharmacol. 89: 69-76.

Glowinski, J., and L. L. Iversen (1966) Regional studies of catecholamines in the rat brain. I. The disposition of $\left[{ }^{3} \mathrm{H}\right]$-norepinephrine, $\left[{ }^{3} \mathrm{H}\right]$-dopamine, and $\left[{ }^{3} \mathrm{H}\right]$-dopa in various regions of the brain. $\mathrm{I}$. Neurochem. 13: 665-669.

Gonzalez-Sastre, F., and J. Folch-Pi (1968) Thin layer chromatography of the phosphoinositides. J. Lipid Res. 9: 532-533.

Janowsky, A., F. Okada, D. H. Manier, C. D. Applegate, F. Sulser, and L. R. Steranka (1982) Role of serotonergic input in the regulation of the beta-adrencrgic reccptor-coupled adcnylate cyclase system. Science 218: 900-901.
Janowsky, A., R. Labarca, and S. M. Paul (1984) Noradrenergic denervation increases alpha-1 adrenoceptor-mediated inositol-phosphate accumulation in the hippocampus. Eur. J. Pharmacol. 102: 193-194.

Kendall, D. A., and S. R. Nahorski (1985) 5-Hydroxytryptaminestimulated inositol phospholipid hydrolysis in rat cerebral cortex slices: Pharmacological characterization and effects of antidepressants. J. Pharmacol. Exp. Ther, 233: 473-479.

Kendall, D. A., E. Brown, and S. R. Nahorski (1985) Alpha-1-adrenoceptor-mediated inositol phospholipid hydrolysis in rat cerebral cortex: Relationship between receptor occupancy and response and effects of denervation. Eur. J. Pharmacol. 114: 41-52.

Leysen, J. E., C. J. E. Niemegeers, J. M. Van Neuten, and P. M. Laduron (1982) $\left[{ }^{3} \mathrm{H}\right]$-ketanserin, a selective $\left[{ }^{3} \mathrm{H}\right]$-ligand for serotonin-2 receptor binding sites. Mol. Pharmacol. 21: 6301-6314.

Lucki, I., H. R. Ward, L. S. Y. Tyau, and A. Frazer (1985) Chronic administration of antidepressant drugs to rats reduces head shake response to L-5-hydroxytryptophan. Soc. Neurosci. Abstr. 11: 634.

Masters, S. B., M. T. Quinn, and J. H. Brown (1985) Agonist-induced desensitization of muscarinic receptor-mediated calcium efflux without concomitant desensitization of phosphoinositide hydrolysis. Mol. Pharmacol. 27: 325-332.

Mayer, G. S., and R. E. Shoup (1983) Simultaneous multiple electrode liquid chromatographic-electrochemical assay for catccholaminc, indoleamines and metabolites in brain tissue. J. Chromatogr. 255: 533 544.

Mogilnicka, E., and V. Klimek (1979) Mianserin, danitracen and amitriptyline withdrawal increases the behavioral responses of rats to L-5HTP. Commun. J. Pharmacol. 31: 704-705.

Nakamura, M., and H. Fukushima (1978) Effects of reserpine, parachlorophenylalanine, 5,6-dihydroxytryptamine and fludiazepam on the head twitches induced by 5-hydroxytryptamine or 5-methoxytryptamine in mice. J. Pharm. Pharmacol. 30: 254-256.

Nelson, D. L., A. Herbert, S. Bougoin, J. Glowinski, and M. Hamon (1978) Characteristics of central $5 \mathrm{HT}$ receptors and their adaptive changes following intracerebral 5,7-dihydroxytryptamine administration in the rat. Mol. Pharmacol. 14: 983-995.

Pazos, A., D. Hoyer, and J. M. Palacios (1984) The binding of serotonergic ligands to the porcine choroid plexus: Characterization of a new type of serotonin recognition site. Eur. J. Pharmacol. 106: 539546.

Pedigo, N. W., H. I. Yamamura, and D. L. Nelson (1981) Discrimination of multiple $\left[{ }^{3} \mathrm{H}\right]-5$-hydroxytryptamine binding sites by the neuroleptic spiperone in rat brain. J. Neurochem. 36: 220-226.

Peroutka, S. J., and S. H. Snyder (1979) Multiple serotonin receptors: Differential binding of $\left[{ }^{3} \mathrm{H}\right]-5$-hydroxytryptamine, $\left[{ }^{3} \mathrm{H} \mid-\right.$ lysergic acid diethylamide and $\left.{ }^{3} \mathrm{H}\right]$-spiroperidol. Mol. Pharmacol. 16: 687-699.

Peroutka, S. J., and S. H. Snyder (1980) Long-term antidepressant treatment decreases $\left[{ }^{3} \mathrm{H}\right]$-spiroperidol-labeled serotonin receptor binding. Science 210: 88-90.

Quik, M., and E. Azmita (1983) Selective destruction of the serotonergic fibers of the fornix-fimbria and cingulum bundle incrcases 5 HT -1 but not 5 HT -2 receptors in rat midbrain. Eur. J. Pharmacol. 90: $377-384$

Rittenhouse, S. E. (1984) Activation of human platelet phospholipase $\mathrm{C}$ by ionophore $\mathrm{A} 23187$ is totally dependent upon cyclo-oxygenase products and ADP. Biochem. J. 222: 103-110.

Roth, B. L., T. Nakaki, D. M. Chuang, and E. Costa (1984) Aortic recognition sites for serotonin (5HT) are coupled to phospholipase $\mathrm{C}$ and modulate phosphatidylinositol turnover. Neuropharmacology 23 . 1223-1225

Roth, B. L., T. Nakaki, D. M. Chuang, B. Chernow, and E. Costa (1985) Characterization of $5 \mathrm{HT}-2$ receptors linked to phospholipase $\mathrm{C}$ in rat aorta. Fed. Proc. 44: 1244.

Samanin, R., J. Mennini, A. Ferraris, C. Bendotti, and R. Borsini (1980) Hyper- and hyposensitivity of central serotonin receptors: $\left[{ }^{3} \mathrm{H}\right]$-serotonin binding and functional studies in the rat. Brain Res. 189:449457.

Sanders-Bush, E., and P. J. Conn (1986a) Effector systems coupled to serotonin $(5 \mathrm{HT})$ receptors in brain: $5 \mathrm{HT}$ stimulated phosphoinositide hydrolysis. Psychopharmacol. Bull. (in press).

Sanders-Bush, E., and P. J. Conn (1986b) Neurochemistry of serotonin neuronal systems: Consequences of serotonin receptor activation. In Psychopharmacology: Third Generation of Progress, Raven, New York (in press). 
Savage, D. D., J. Mendels, and A. Frazer (1980a) Decrease in $\left[{ }^{3} \mathrm{H}\right]-$ scrotonin binding in rat brain produced by the repeated administration of either monoamine oxidase inhibitors or centrally acting serotonin agonists. Neuropharmacology 19: 1063-1070.

Savage, D. D., J. Mendels, and A. Frazer (1980b) Monoamine oxidase inhibitors and serotonin uptake inhibitors: Differential effects on $\left[{ }^{3} \mathrm{H}\right]$ serotonin binding sites in rat brain. J. Pharmacol. Exp. Ther. 212: 259-263.

Schacht, J. (1981) Extraction and purification of polyphosphoinositides. Methods Enzymol. 72: 626-631.

Seeman, P., K. Westman, D. Coscina, and J. J. Warsh (1980) Serotonin receptors in hippocampus and frontal cortex. Eur. J. Pharmacol. 66 : 179-191.

Stoltz, J. F., C. A. Marsden, and D. N. Middlemiss (1983) Effect of chronic antidepressant treatment and subsequent withdrawal on $\left[{ }^{3} \mathrm{H}\right]-$ 5-hydroxytryptaminc and $\left[{ }^{3} \mathrm{H}\right]$-spiperone binding in rat frontal cortex and serotonin-mediated behavior. Psychopharmacology 80: 150-155.

Van Dongen, C. J., H. Zwiers, and W. H. Gispen (1985) Microdetermination of phosphoinositides in a single extract. Anal. Biochem. 144: 104-109.
Watson, S. P., M. Wolf, and E. G. Lapetina (1985) The formation of $\left[{ }^{3} \mathrm{H}\right]$-inositol phosphates in human platclets by palmitoyl lysophosphatidic acid is blocked by indomethacin. Biochem. Biophys. Res. Commun. 132: 555-562.

Wong, D. T., and F. P. Bymaster (1981) Subsensitivity of serotonin receptors after long-term treatment of rats with fluoxetine. Res. Commun. Chem. Pathol. Pharmacol. 32: 41-51.

Yagaloff, K. A., and P. R. Hartig (1985) ${ }^{125}$ Iodo-LSD binds to a novel 5HT site on rat choroid plexus epithelial cells. J. Neurosci. 5: 31783183.

Yamamoto, T., and S. Ueki (1981) The role of central serotonergic mechanisms on head-twitch and backward locomotion induced by hallucinogenic drugs. Pharmacol. Biochem. Behav. 14: 89-95.

Yavin, E., and A. Zutra (1977) Separation and analysis of [ $\left.{ }^{32} \mathrm{P}\right]$-labeled phospholipids by a simple and rapid TLC procedure and its application to cultured neuroblastoma cells. Anal. Biochem. 80: 156-160.

Zatz, M. (1985) Denervation supersensitivity of the rat pineal to norepinephrine-stimulated $\left[{ }^{3} \mathrm{H}\right]$-inositide turnover revealed by lithium and a convenient procedure. J. Neurochem. 45: 95-100. 